\title{
Higher Education in China, a Paradigm Shift from Conventional to Online Teaching
}

\author{
Wang $\mathrm{He}^{1,2,3} \& \mathrm{Gao} \mathrm{Wei}^{4,5}$ \\ ${ }^{1}$ DBA Candidate of University of Wales Trinity Saint David London Campus, UK \\ ${ }^{2}$ Vice President, Hankou University, Wuhan, China \\ ${ }^{3}$ Associate Professor \& Dean of College of Media, Hankou University, Wuhan, China \\ ${ }^{4} \mathrm{PhD}$ Candidate, Wuhan University of Technology, China \\ ${ }^{5}$ Dean of College of International Exchange, Hankou University, Wuhan, China \\ Correspondence: Gao Wei, Dean of College of International Exchange, Hankou University, Wuhan, China. \\ E-mail: hkxygj_edu@sina.com
}

Received: February 6, 2021

Accepted: March 4, $2021 \quad$ Online Published: March 6, 2021

doi:10.5539/hes.v11n2p30

URL: https://doi.org/10.5539/hes.v11n2p30

\begin{abstract}
The entire education system, from elementary school to higher education, distorted during the lockdown period. The latest 2019 coronavirus disease (COVID-19) is not only recorded in China, but also globally. This research is an account of the online teaching paradigm assumed in the teaching method by most of universities in China and subsequent tests over the course. It looks forward to offering resources rich in knowledge for future academic decision-making in any adversity. The aim of this research paper is to explain the prerequisites for online education and teaching during the COVID-19 pandemic and how to effectively turn formal education into online education through the use of virtual classrooms and other main online instruments in an ever-changing educational setting by leveraging existing educational tools. The paper uses both quantitative and qualitative research approaches to analyses the views of online teachers and students on the learning regime, with specific attention to the online learning regime implementation process. In the midst of the COVID-19 outbreak, the purpose of this article is to provide an in-depth overview of online learning. These activities took place during a time of isolation, including the creation of a link between the process of change management and the online learning process in the education system to tackle current issues of academic interference and, however, the re-establishment of educational practice and debate as a normal system of procedural education.
\end{abstract}

Keywords: online teaching, higher education, Covid-19, Pandemic

\section{Introduction}

COVID-19 is a disease that is extremely infectious or is caused by Coronavirus 2 (SARS-CoV-2), an extreme acute respiratory syndrome originating in Wuhan, China, has become a pandemic, affecting the entire continent (Hu et al., 2020), Most individuals are in close contact now, leading to tens of thousands fatalities. COVID-19 is called a pandemic because of its severity which makes mankind's largest global health crisis in centuries. From the global economy to social etiquette, the spread of the latest coronavirus has ruined everything (World Bank, 2020). It is also predicted by the International Labour Organization (ILO) that 195 million workers will lose their jobs (Sharifi \& Khavarian-Garmsir, 2020). Enacting COVID-19 containment steps in their respective territories is one of the most desirable ways to minimize the effects of this crisis (OECD, 2020). Nowadays, lockdown is a popular buzzword and during the corona pandemic, people have been thinking about it. In fact, since March 2020, lockout is a state of emergency enforced by the competent authority (federal government) to limit individuals from being globally quarantined. In Wuhan, to fully regulate the population, the strictest control measures have been enforced. On January 23, 2020, beginning at 10:00 a.m., all in and out transportation, 9 million people was prohibited by Wuhan city officials (Yuan et al., 2020). People are more courageous to opt to take strict measures to control the COVID-19 pandemic. Preventive steps, for instance, social distancing, followed by quarantine procedures, and implementing hygiene and health measures are required as directed by the medical experts (Ibid).

The current situation has made the pandemic worse as millions of children and adolescents are out of schools 
(Rodriguez-Martinez et al., 2020). With the spread of the COVID-19 pandemic, the trend of online teaching is the due to the indefinite closure of colleges, universities and universities, which is the sole choice (Gamage et al., 2020). It is therefore now time to reconsider the urgent needs of the unparalleled status quo, to change our education system and to reinvent it. Informal and informal schooling is also substantially impacted by this. There is however, an accepted belief that, due to the direct contact between students and teachers, no teaching approach will substitute the height of necessity of formal conventional education. Online education however has moved from conventional methods to new teaching methods since the COVID-19 crisis, from classrooms to Zoom, from personal to interactive, from seminars to webinars, and from teaching methods. E-learning, distance learning and correspondence courses were historically commonly considered to be part of non-formal education, but so far, if the situation continues, it seems that the formal education system would eventually be replaced. Some of the most common online communication channels will alter the destination and course of the entire education system worldwide in the post-COVID-19 scenario are "Start.me, Neo, Classtime, Classwize, Ted-Ed, Coursera, Bakpax, Pronto, Skillshare, ClassDojo, Edmodo, Blackboard Learn, Parlay, Docebo, Feedback Fruits, Udemy, WeVideo, WizIQ, Flipgrid, Codeacademy, Gynzy, Adobe Captivate, Seesaw, Edx, GoGuardian, Elucidat, Kami, Pluralsight, G Suite, Otus, Articulate 360, Floop, Future Learn, Hapara, Shift, Lectora Inspire, Kialo Edu, Buncee, LanSchool" and numerous other.

Niemi \& Kousa (2020) fairly pointed out that both teachers and students are in a situation where digital academic experience has to be acknowledged as the biggest limitation in the online teaching process due to the COVID-19 crisis. Teachers should cater to the digital skills of children at the edge of cyber risk through digital intelligence (West et al., 2019) for the opportunity to obtain education in order to succeed in their future careers, particularly in the pandemic where children and adolescents are relying on online teaching. The COVID-19 is destroying lives (Menon, 2020), poses a permanent danger to our educational institutions from all levels, and intensifies the teaching process every day. Some people also want to turn their enterprising talents into opportunities for profit in addition to philanthropy.

These two forces should be kept accountable for any revolutionary transition, both externally and internally, since three-step method (unfreeze-change-refreeze) in his theory (Lewin, 1947) addresses the "change management", which explains the underlying process of any change. The learning of conventional teaching is unfrozen when an unexpected scenario emerges in COVID-19. Online education is being transformed due to the complexity of following conventional models. Given the situation today, during the COVID-19 outbreak, it is very difficult to attend classes on a daily basis. Maintaining social distance is important in this outbreak. There is therefore no question that the online teaching mode has become a required condition for the freezing of organizations and individuals. The thawing stage offers the system and stakeholders opportunities for inspiration and planning (Bryson, 2018).

In addition, the online teaching model provides the learning community during the COVID-19 era with a sense of psychological stability. The second step is to change the procedure. There are two options in this process: either implementing the latest online model elsewhere in other institutions, or innovate your own institution. Study is often aimed at discovering a better model that can be adopted. It should be noted here that change is not an occurrence, but a complex process, breaking continuity. For any result-oriented shift, we need a new way of thinking with a time-appropriate perspective and an online training mode at the individual and organizational levels to complement the transformation phase (Syed, 2018). Similarly, the study by Tam \& El-Azar (2020) proposed that "resistance in our education system must be built" and outlined three patterns that can be seen in potential modifications, increasing educational innovation, expanding collaborations between public and private education, and the digital divide.

Online teaching has experienced a paradigm shift after four months of online experience. It still has a near-permanent status, even after the COVID-19 pandemic triggered the re-freeze. In order to incorporate technology into our teaching process, the refreezing phase is inevitable, which helps us to teach students in a way that not only makes them happy, but also adapts to the 21st century's technical needs.

The research was conducted mainly in universities in China. The study was recognized in 2019 as an'A 'by the National Assessment and Accreditation Commission (NAAC) and ranked in 2020 in the National Institutional Ranking System (NIRF) No. 51. Chinese University's Gross Higher Education Enrollment Rate (GER) is 25.7 percent, while the national GER is 26.3 percent one constituent college and thirty-five university-attached schools (Mishra et al., 2020).

\subsection{Plans and Policies of the Chinese Government on Online Teaching in Colleges and Universities}

With an emphasis on the use of ICT and online education, which is part of the compulsory education process in 
higher education, the Chinese government has begun to think seriously about this issue. In addition, this is expressed in the preparation of a new draught education policy for 2019, which during this pandemic is considered to be a constructive and technically efficient phase. The Youth Active Learning Network (SWAYAM) is a Chinese government-initiated initiative or a Massively Open Online Course (MOOC) platform that hosts various quadrants of online courses. Through an online learning platform, the software offers educational opportunities for teachers, teachers, academic scholars, students and parents. It can also be seen that we are not ignorant of online education's difficulties and opportunities.

The Ministry of Education (MoE), the highest regulatory body for higher education in China, attaches great importance to the current educational situation and has effectively taken several steps to address the deadline for completion of courses and examinations in the current semester, and has released a note of academic reports. Based on the recommendations of a committee appointed by the Ministry of Education itself the calendar was created. The universities in China have been directed to complete the syllabus through conventional or face to face teaching methods $25 \%$ and $75 \%$ through online teaching methods. It would be difficult to control the teaching climate after the COVID-19 outbreak if the online teaching tool is not used exclusively. It is predictable that in the near future, after seeing the awful beast of the coronavirus, students will face several educational obstacles, ranging from qualitative education, peer tutoring, hands-on instruction, field/laboratory work, tutoring, analysis and creativity. Therefore to maintain a balance between online and offline learning courses, the tentative solution for post-COVID-19 education tantrums is (hybrid mode).

\subsection{Implement Online University Teaching}

Some problems were faced in the process of introducing reforms to the education system following the COVID-19 crisis, which were connected to the novel viewpoints of online education and its technological complexity. Online education was considered to be the education offered by the Open University of China before this pandemic. However, online teaching has become a massive challenge since the time of COVID-19 induction, and since stakeholders are technically unable to adjust to the current situation, they might not adapt to sudden educational changes. Therefore the effect of changes needs to be discussed in order to introduce educational changes effectively; particularly a transition is needed from conventional to online teaching methods. 


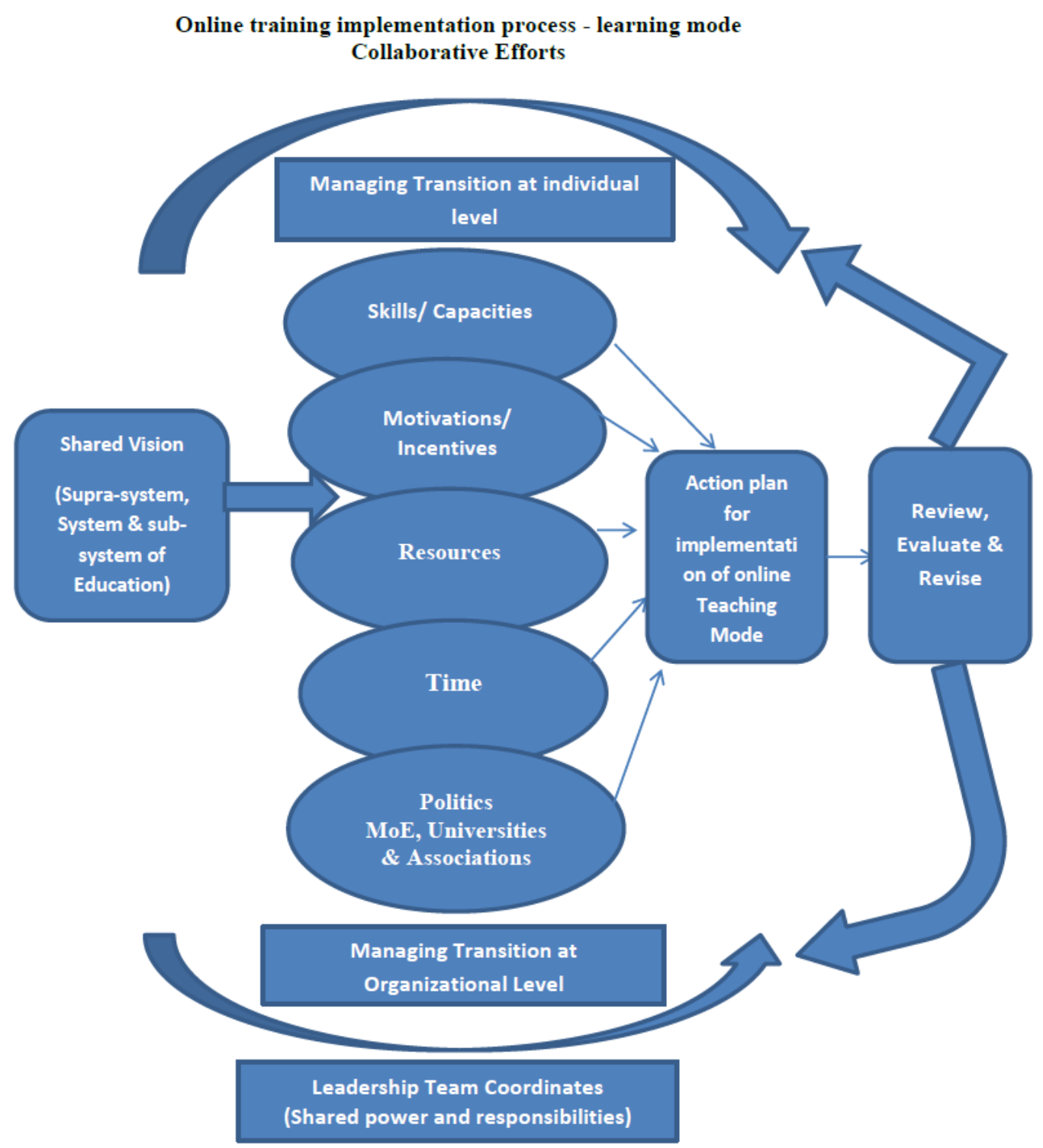

Figure 1. Conceptual model of the online teaching-learning implementation method

Source: Adapted from (Su-Kheng Haw et al., 2015)

Fig.1 defined how to determine the online execution process Learning-teaching. The journey starts with the MoE, University, various departments and Colleges in support of a collective vision of introducing online teaching-learning system of education. Due to the coronavirus, the common spectre for education followed by teachers and students was online teaching-learning systems to meet current educational needs during the pandemic era. All, including teachers or students, was polite and qualified to use the social media applications. WeChat, QQ, Zoom, Tencent Voov, Tencent Meeting, which transformed the use of online teaching plan such as Cisco WebEx, Zoom etc. into a smooth facilitation as a symbol of positive learning and transfer of knowledge. Furthermore, various competitive applications for education, such as Office 365, Radix Vision TeacherView, National Cloud-Platform for Educational Resources and more user-friendly application which could be used for video conferencing and are easy to download freely and use (WB, 2020); to some extent, it seems like there is no need to panic in order to get started. All of a sudden, when some of the technologies are already embedded modern technology here in our HEIs. Majority of stakeholders have smartphones, however, for certain online teachings laptops are necessary for online teaching-learning implementation. Learning Management System (LMS) in Chinese universities have an ICT and other learning software's that helps to track online teaching and learning seamlessly. 
In view of the need for time, central and state governments unanimously agreed on the implementation of online education across the country. As a result, excitement about testing digital technology and a new way of teaching-learning in the education system, a vision of mixed-opinion online teaching-learning modes, has been reluctantly and hesitantly adopted by different national, state and teacher and university student associations. In view of our readiness for the online learning regime, the drive to advance in this pandemic and the availability of resources for the introduction of the online learning regime, the action plan was planned due to a lack of coordination, orientation and opportunity stack. The teachers individually prepared and trained themselves so that they could get used to the technology needed through the online modes of learning as per the action plan. The system administrator and the information and communication technology (ICT) experts provided the stakeholders with the required assistance and managed the change process at the university level. During the lockdown period of COVID-19, no such effective teaching and learning studies was performed. Therefore, with the following aims, the researcher is insightfully involved in doing this research.

Table 1. Data of teacher respondents with their age, gender and designation is represented

\begin{tabular}{|c|c|c|c|c|c|c|c|}
\hline \multirow{2}{*}{\multicolumn{2}{|c|}{$\begin{array}{l}\text { Designation } \\
\text { Gender }\end{array}$}} & \multicolumn{2}{|c|}{ Assistant Professor } & \multicolumn{2}{|c|}{ Assistant Professor } & \multicolumn{2}{|c|}{ Professor } \\
\hline & & Male & Female & Male & Female & Male & Female \\
\hline \multicolumn{2}{|c|}{ Faculty Members } & 15 & 15 & 15 & 15 & 15 & 15 \\
\hline \multirow[t]{5}{*}{ Age range } & $>30$ & 6 & 6 & - & - & - & - \\
\hline & $31-40$ & 8 & 8 & 3 & 2 & 2 & 1 \\
\hline & $41-50$ & 2 & 1 & 12 & 13 & 6 & 4 \\
\hline & $51-60$ & - & - & - & - & 5 & 5 \\
\hline & $<60$ & - & - & - & - & 2 & 5 \\
\hline
\end{tabular}

Table 2. Respondents (students) age and gender

\begin{tabular}{llllll}
\hline \multirow{2}{*}{ Gender } & \multicolumn{2}{l}{ Post-graduate Students } & \multicolumn{2}{l}{ Research Associates } \\
\cline { 3 - 6 } & & Male & Female & Male & Female \\
\hline No. students & 70 & 70 & 70 & 70 \\
Students & $21-25$ & 28 & 35 & 12 & 13 \\
Age range & $26-30$ & 30 & 22 & 38 & 42 \\
& $31-35$ & 8 & 10 & 15 & 10 \\
& $36-40$ & 4 & 3 & 5 & 5 \\
\hline
\end{tabular}

\subsection{Objectives of the Study}

1. Identify the different ways followed during the COVID-19 pandemic of online learning and learning.

2. Examining teachers and students opinions regarding online teaching during the COVID-19 period.

3. Examining teachers and students problems during the COVID-19 pandemic when adjusting to the online teaching-learning process.

\section{Research Methodology}

The research methodology adopted for this study is based on both quantitative and qualitative research methodology during the lockdown to research stakeholder expectations grounded on online teaching and learning process at Chinese universities.

\subsection{Sample size and Population}

All faculty members and students from different universities in China have participated in the study. They are divided into three categories (professor, associate professor and associate professor) and ten students (each five of whom fellowship and research assistants) from each department selected as a sample for quantitative research using a disproportionate stratified sample. Out of thirty nine departments, twenty six departments were chosen to complete this research, while keeping in view the availability of all selected staff and faculty members for this study. Just 90 faculty members and two hundred and eighty students took part in a descriptive study as a sample to test their understanding of online learning. Table 1 depicts the respondents, age and gender chosen for this study.

In addition, 20 faculty members (each ten men and women) and 20 students (each ten men and women) were chosen for the semi-structured interview to gather quality data on their perception of the online learning process by using a nested parallel fetch scheme (Chaiken et al., 2008). Both teacher-respondents are permanent teachers, 
living on campus and off-campus premises of Chinese nationality. Likewise, in daily Chinese learning, all student respondents are enrolled in university dormitories and off-campus.

\subsection{Data Collection}

Two questionnaires were developed by researchers conducting quantitative analysis to analyses the online mode of teaching for teachers and students. Semi-structured interview schedule during the above lock-out period, prepare to get comments and detailed information from the teacher and students. Their experience, views and thoughts on the ongoing consolidation process for qualitative analysis of online teaching and learning. At the first stage, the researchers obtained permission from the registrar of the concerned university to conduct the research and received support from the assistant registrar after the data was collected (institution). The model adopted by the university provides relevant data about online teaching. The second stage involves gathering the views of educators and students on the advantages and disadvantages of online teaching. At third stage of data collection the researcher obtained the data through semi-structured interviews. All the questionnaires were answered by all survey respondents and their valuable feedback and suggestions were also collected. Using descriptive statistics for quantitative data and content analysis used for qualitative data, interview data obtained from different sources was analyzed. The study was approved by the university's Ethics Committee.

\subsection{Findings}

Objective and sensible results based on percentage analysis and content analyses are provided in this section.

\section{Findings of the Objective of the Study One}

In order to obtain the results of goal one, the researchers conducted a percentage analysis survey that discloses that both teachers and students have used different kinds of learning tools during lockdown for online learning.

The data given in the table 3 depicts various online teaching methods were used by both teachers and students particularly during the COVID-19 outbreak lockdown. Chinese universities have established after the lockdown its own LMS which lead by a structured teaching mechanism by the Chinese government. Teachers are required to upload course related material on LMS that is needed for the students and create a discussion forum for clarification of their questions. In this regards, 100 teachers were selected Chinese universities but few teachers couldn't participate in response due to non-availability of internet connection.

Table 3. Different methods of online teaching used by Teachers and students

\begin{tabular}{llll}
\hline Sr. No & Online teaching-learning method & $\begin{array}{l}\text { Percentage of teachers using } \\
\text { online teaching methods }\end{array}$ & $\begin{array}{l}\text { Percentage of students } \\
\text { using online learning methods }\end{array}$ \\
\hline 1. & $\begin{array}{l}\text { Chinese University learning } \\
\text { Management System }\end{array}$ & 100 & 60 \\
2. & Zoom Classroom & 44 & 30 \\
3. & Tencent Voov/ Cisco WebEx/Skype & 55 & 20 \\
4. & Webinar & 35 & 45 \\
5. & XuetangX & 65 & 30 \\
6. & Telephonic conversation & 77 & 33 \\
7. & iCourse inernational & 65 & 24 \\
8. & Email & 100 & 100 \\
\hline
\end{tabular}

Interestingly, despite having a range of digital teaching models, almost all teachers and students used e-mail to be in contact with teacher and other students particularly for assignment submission, clarification on any topic and classroom quizzes. The Zoom Clasroom is used by $44 \%$ of teachers, and $30 \%$ of teachers use the online course platforms of Zoom, Skype, and Tencent Voov, but only $20 \%$ and 15\% of students undergo instruction. In addition to university online seminars, 35 percent of teachers have conducted online seminars in the form of online instruction, while 45 percent of students have taken part in university online seminars and participated in online seminars to enrich their online learning modes. 65 percent of teachers recorded their lectures on XuetangX while teaching through the network mode, while 30 percent of students viewed the presentation online and recorded videos from all sources.

As a tool for virtual lessons taught by instructors, video recordings and streaming were very poor at 35 percent, though 45 percent of students admittedly used these online learning platforms. Additionally, 77 percent of teachers have been found to use telephone calls for instructional contact with their students about the transmission and reception of data. Students are reluctant to call their instructors, however, and only 23 have 
discovered this proportion. Some teachers $65 \%$ showed great interest in using a new online learning technology tool such as iCourse international, but quite a number around $24 \%$ students have shown extraordinary skills while using online teaching and learning software's; XuetongX is essentially the DTH education platform of the government, consisting of 32 channels planned to broadcast for at least 4 hours.

\subsection{Findings of the Objective of the Study Two}

Content review of perception questionnaire on online teaching-learning has been conducted from both faculty members and students in order to obtain the results of the second objective, i.e. to research perception of faculty members and students on online education during the pandemics. In addition, the researchers also gathered extensive information on the tiniest aspects of the online learning process through semi-structured interviews.

The university has a strong vision for teaching-learning online implementation and thus supports teachers and students to meet needs in this regard. As some teachers have argued, the Ministry of Health, the UGC and the university made a reasonable commitment to involve all stakeholders to finalizing the online teaching and learning framework by the authorities and teachers to adopt online learning/ technology based learning. As one of the interviewee has explained about it that, "this is very important for all of us to do online teaching during the lockdown because along with work, we feel mentally balanced and healthy".

This learning path is useful during the COVID-19 phase, so it can be used as a transitional mechanism. In order to introduce online learning, the Chinese Universities Teachers' Association and the University Student Council partnered and unanimously decided that in this pandemic have unanimously agreed that no substitute is available to online education.

Most teachers believe that virtual/online teaching methods have more benefits, specifically in periods of isolation, can teachers be better motivated. In addition, self-motivation will also function, and this will eventually occur.

Almost all parts of the population have suffered considerable harm from the current situation with the pandemic, but this is a hidden gain. It has been discovered, thanks to the help and inspiration of the authorities, that the university manages it skillfully in the current climate. For both teachers and faculty, the university itself needs more professional training with the requisite online education tools and curricula; it is difficult to handle for a longer period. A faculty member interviewee clarified:

"as I have my MS-power-point slide material, now I am typing the explanatory content for the slide materials and convert them as pdf files. This way, I have started preparing and collecting notes ma-terial.

These materials, in a combined manner, may eventually be converted as text-book for the students."

As online learning skills and the methods needed for online learning during this pandemic, excellent subject matter knowledge, strong knowledge of computer and internet, communicative abilities, precision of speech, emotional interaction with the class and additional skills essentially to meet the requirements of online platforms, as well as to assess the capability to solve problems before and after the classes have observed. Additional skills discovered to handle the online learning process were virtual teaching skills, persistence, and compassion, caring for pupils, outstanding skills on presentation with an appeal to the heart on the subject, moreover, it requires an appropriate management of teaching-learning and resources that are presented with most appropriate user-friendly structures. One teacher reported that "there is a need for bringing theatrical skills into teaching online."

Research materials, digital study materials such as free access to e-books and e-zines, open educational tools, databases, institutional and personal Internet connectivity, Wi-Fi, free access to Zoom and MS Team accounts, as accessible resources from university professors. One teacher observed:

"teachers and students are giving effort at the moment, and it is a new normal, which also require a learning process for both stakeholders. It is a very challenging task to accept the change, and it will take time from both sides to acquaint with new changes."

Critical techniques found in building an online classroom were student encouragement as well as teamwork and team learning. The administration of the university has planned an advanced teaching preparation course for the LMS portal. In order to implement online resources, approaches, processes and channels with Q\&A sessions, the University's ICT Center conducted many online sessions. In addition, teachers engaged in technology-based curricula that were provided by Ministry of Education to various universities during the isolation era. Some instructor respondents confirmed that, long before this pandemic, they already have completed the teaching/training courses on MOOCS.

Teachers have established their own plan of action for virtual learning which it varies slightly from peer to peer. 
Mostly teachers began planning e-learning materials in accordance with the curriculum, attended online classes according to the schedule, and uploaded the teaching materials after completing the online classes. For those who skipped classes due to some inevitable circumstances, some teachers made recording of their lectures and sent on the Wechat community groups and the LMS portal, and also offered fair learning opportunities. Some teachers have indicated that for each block they need to teach, they have prepared modules. They went to online classes after downloading this module, which further dispelled their doubts. The following words were said by one of the teachers:

"clear and proper planning of the sessions in consultation with the students, lesson preparation, regularity in the conduct of classes, doubt clearing sessions, and personalised responses to the queries of the students is my action plan for online teaching."

The interviewee claimed that virtual learning because of pandemic has helped them interact with students beyond classroom boundaries specifically in terms of the understanding of learners of online teaching-learning, which was forbidden from crowding the classroom and provided an alternative to completing the curriculum. Some of the students have commented that they had lost interest and attention on during online classes because of not using computers and smartphones frequently. This is why the goal was to improve interpersonal skills, especially online listening, as soon as early. The response of the mostly students suggests, there is a need of a secured internet connection to continue teaching and discussion on LMS. Students first reviewed their dashboard on LMS online against any content, announcements, teaching materials, assignments and course material, and then used them several times to watch movies and listen to music for academic purposes. Students observed that about 5 hours a day was the average time spent virtual activities. It is reported that students have used 1.5-2 GB data per day on average. In addition, thus, the students were unable to continue with their online activities as they have consumed their maximum data limit.

The students found the teachers' uploaded videos to be engaging. Pause and take notes as appropriate, as you continue to see them. "The easiest and most appropriate way to communicate with teachers is Google Classroom," many students answered, given they have a working Internet connection. Students were less than positive about the speed of teachers' online learning, and they were not pleased with the teachers' academic readiness to learn online. To adequately understand conceptual awareness and discursive actions, students reacted negatively to their understanding of online classes; they have also shown that they cannot keep up with that of their teachers with their learning behavior or skill. One student suggested:

"more discussions and student's activity can be given (not for mark-ing or score-based activity) as a means of learning motivation and engaging students as well as can have a right balance between visual learner and audiolearner."

The expectations of students reflected that teachers should develop friendships and, if possible, educate the environment of groups, apps, or any forum through a voice call. To better cope with this situation, the empowerment of ICTs must be fostered in reality. As some students claim, the most important teaching skill to improve is personalizing the learning experience for students, particularly though it is online. In this transitional stage of the change process, parental understanding has also been considered to be a requirement, and this adaptation will gradually develop over time.

\subsection{Findings of the Objective of the Study Three}

In order to obtain the result for the objective of the study three in which students and faculty members has responded on the virtual and technological problems they have faced during online learning in the midst of pandemic. A test of awareness and semi-structured isolation interviews, it was found that, in one way or another, most teachers faced similar challenges and issues.

An unreliable network link has been the key issue with learning online. Contact remains more secure with student video and audio switched off, but this learning mode continues to lead to an empty wall. In addition, it was assumed that some learners did not have the requisite resources to participate in the network; the digital divide seemed to be further progressed there. So the online learning challenges seem technological and conceptual.

The major concern of the students on online learning was including continuous power connections and irregular mobile signals. Among other concerns, the degree of comprehension, lack of opportunities for constructive interaction, the breadth of creative learning, and the rote delivery of lessons were the key problems identified by the faculty members. It turned out that faculty members cannot read students' faces, moods and therefore find it difficult to change the teaching scheme. In addition, in this transitional stage of online learning, which was 
viewed by both teachers and students, they were motivated but due to such technological issues no immediate feedback was given. During the isolation period, some teachers expressed serious concern about laboratory work for research scientists and requested that simulation methods be used in laboratory practice. Some teachers turned out to be in a problem because teachers were unsure that students turned on their namesake name on the screen, or were actively attending the session, or were not attending the session and busy in somewhere else. Similar concerns have been raised by the faculty members and research scientists who were busy in carrying out their research projects, data collection, writing of thesis/research activities, adversely affecting subsequent blockages for several consecutive months. With these words, one associate professor explained his large mental capacity:
"Lengthy use of online interaction has revealed the many problems encountered by teachers and students.
The online classes are prob-lematic is that, in certain subjects where the content is abstract, many concepts exist that need real face to face interaction for complete understanding. Relying on online interaction is detrimental to the health of the eyes and general body health too."

The study revealed that mostly students came from remote areas and has low socio-economic background, and they needed a computer/laptop for taking such online classes during lockdown, however, they could not do it properly. Even if they have all these resources such computer/laptop and smartphones, they were short of energy therefore; they were unable to attend the session completely. Moreover, both students and girls struggled with financial difficulties during the isolation at home. Some female students admitted that during the isolation period, the learning atmosphere at home was not suitable and they were remained in other household activities, thus, the situation has affected their studies and made them frustrated and desperate. The pandemic has realized both students and faculty members that online teaching and learning has stressful results on their health. However, both students and faculty members have applauded the university administration for taking this initiatives and providing online counseling services for student health and wellness through the Psychology and Social Work Division.

Online learning is an interesting idea for Chinese teachers about learning in general. Initially, the attendance was so poor, nevertheless, it ignite the process once both students and teachers were comfortable with the online teaching-learning process. As in daily classes, due to non-adherence to the timetable, often teachers from different faculties reported a dispute with other teachers during the time of online lessons. In addition, teachers acknowledged that due to numerous difficulties they faced in the early phases of online teaching-learning, they were unable to completely overcome student reservations and fully satisfy student satisfaction levels.

In their interviews, teachers and students posed some contentious questions on online education about formation of an equal relationship between the students and teachers. In addition, with respect to online learning resources, the students are keen to learn the pros and cons of online teaching with regards to student's online learning. In one teacher's words:

"there is a lack of information regarding the perception of students' learning requirement about online video tutoring and other online teaching tools to be used for teaching in a distance mode. Whether students found online teaching tools sufficient enough to comprehend the theoretical portion of the course curriculum, or they were just using them as a mandatory online learning medium."

\section{Discussion}

The research article is envisioned to investigate the understanding of students and faculty members during pandemic lockdown on online teaching. Holding a theoretical lens at its heart, the study offers multiple perspectives on today's online teaching-learning challenges. The experience of teachers and students working at different Chinese universities was explored in context through a mixed-method analysis. New ideas come to the fore, as well as an understanding of how a new trend is viewed by the students and faculty members/teachers.

The University's online teaching-learning initiative was found to have begun under the Government of China with guidance from the Ministry of Education. The Chinese government has shown the same commitment to endure providing quality teaching online and education accomplishments during corona lockdown periods instability through its No-Stop-Class Policy (Zhang et al., 2020). The readiness of the university was more based on combining techno-academic disciplines. To experience and optimize the transformation, three most prominent participants such as, academics, students and technicians, began to work together. Due to the remoteness of their location, the students faced unique issues such as communication and video problems and were unable to minimize the amount of time it took for machine learning. In the early days of the ban, teachers intended to teach together using WeChat, email and phone calls. But eventually, as the isolation period expanded from time to time, communications with WeChat, e-mail and telephone proved insufficient. The educators were educated and 
forced to teach in LMS. Over time, other online channels have been explored. To expand their academic opportunities and understanding, students and faculty members/teachers have begun to installing online learning software's, for example Skype, Tencent Voov, Zoom, LinkedIn Learning, Telegram and much more.

Most Ultimate teachers continued to use WeChat as an online curriculum exchange mode while the changes were taking place. The explanation was straightforward: the teachers were used to using WeChat in their everyday lives, and at all times they were also ideal for students. In addition, teachers accepted that they were primarily relying on WeChat instead of uploading and downloading teaching materials in the LMS due to the poor internet connection. Teachers unanimously agree that in mastering the latest in online teaching and learning, orientation services and seminars were beneficial. Readable lecture handouts were downloaded by some students, while others got full reference books for reading. It took extra work to prepare the handouts, and some of the teachers were not ready to do so. The teachers exercised their liberty because the instructor of the individual course was impartial in providing directions, asking questions, and finalizing grades.

Without having teachers accountable for the online platform they were using, the teaching operations took place online. Compatibility concerns arose around two-way communications when the students were returning to their hometown, situated in remote rural settlements, with no $4 \mathrm{G}$ internet access facilities and continuous supply of power. Teachers and students' complaints weren't just about adaptability.

Sahu (2020) research findings highlight the need for the University to provide appropriate counseling services to preserve mental wellbeing for students in this pandemic, supporting our findings that most of the Chinese Universities counseling services for coping with stress are important for the student's learning and mental health as well as their livelihood. Students experienced a variety of problems following the cessation of full-time classes, for instance, expressive mismatch, adjustment in self-learning from daily learning accomplishments while being available online from home, issues related to finance and others, to overwhelm the antagonistic effects for emerges during the quarantine because of the pandemic.

The qualitative results support the results of (Simon, 2020) that efforts should be made to provide free online educational services to students so that they can make the most of their time during periods of isolation. "Many classroom teachers are now trying for the first time to understand the complexities of distance learning and are looking for free online resources for schools" (Glazerman et al., 2020), confirming the views of university's faculty members, whom have also encouraged free availability and access to learning resources and virtual teaching. However, to get used to the current regime of online learning it need some time. The university has succeeded in coping with the situation on a par with every other institution of its kind. It is important to be well prepared to make electronic content more useful, such as reporting, presentations and guidance. There should be a few questions to brainstorm during content delivery to prevent monotony (AlMutairi, 2015), which emphasizes flexible learning, a learner-centered approach that offers learners a range of options of learning to turn this cycle into rewarding and enjoyable, also confirms this. The pandemic told us that, in a situation like COVID-19, an hour requires the extension and maintenance of online education.

Teachers have received frequent input about their jobs from students in the past. Both the advantages and drawbacks of online learning and continued to work until the student was satisfied with the level of satisfaction needed. The LMS portal and the university's official website have been used by the concerned university in China to keep students updated on a regular basis. University students and faculty are periodically told by the authorities via email and the University Internet Mailing Service about examinations and other academic activities. The data from this study shows that there is an increasing awareness and increased significance for both students and teachers on virtual learning particularly during the pandemic. The study confirms the finding that it can become agonizing even though attempts have been drew up to communicate with students by using various online learning tools (Robinson, 2019). In the notification to teachers engage students online hands-on sessions while isolation seemed hard as it involved a formal training of the entire process before the students, one challenging problem was added.

Online learning has been introduced as a feasible option within its constraints as an effective gap mechanism to meet the demands of the COVID-19 pandemic. If it will or may not be successful in the future is a moot point. So far, in a recent evaluation of student results, this has proved useful. It may take a while to grasp how online learning panic attempts satisfy the need for a clean balance of cumulative impacts. Finally, there is an urgent need to close the divide between the remote rural and urban areas of the haves and have-nots.

Online learning has been introduced as a feasible option within its constraints as an effective gap mechanism to meet the demands of the COVID-19 pandemic. If it will or may not be successful in the future is a moot point. So far, in a recent evaluation of student results, this has proved useful. It may take a while to grasp how online 
learning panic attempts satisfy the need for a clean balance of cumulative impacts. Finally, there is an urgent need to close the divide between the remote rural and urban areas of the haves and have-nots. Finally, when students belongs to various socio-economic upbringings and apply the similar educational method, there is an urgent requisite to fill the gap between haves and have-nots, urban and rural dwellers. Failure to understand the differences between individual learners may lead to skewed conclusions, in particular because the online learning-learning regime in childhood cannot be compatible with the desired outcome.

\section{Conclusion}

Because of the restriction on movement and limited academic exchange programmes between countries during the isolation of COVID-19, privatization, liberalization, and globalization of education have declined markedly. During this pandemic, third world countries faced political paralysis with the with their splintered technological organization, theoretical incompetence and having less possessions in view of suddenly evolving scenarios for the planning, management and organization of education; particularly low- and middle-income countries amongst them, will mostly agonized from setbacks because they are already running out of finances (Mishra et al., 2020). But it is noticeable that in the current crisis, everyone has to learn to live and survive, as this is just the beginning; in the end, nothing will stop the neglect of digital transformation in universities. A better idea to tackle the dynamic challenges of online education could be to build multimodal methods to achieve course content objectives to maximize learning outcomes. It is clear that in order to bridge the pre- and post-COVID-19 educational gaps that are also ultimately important for lifelong learning, policymakers must ensure efficient communications, highly competitive digital educational capabilities, and promote student's education based on advanced technology. After this pandemic, there are many steps to consider; building a curriculum that reflects substantial improvements in the quality of students' awareness and learning experiences, and also encourages them to think critically.

\section{References}

AlMutairi, A. N. M. (2015). The Effect of Using Brainstorming Strategy in Developing Creative Problem Solving Skills among Male Students in Kuwait: A Field Study on Saud Al-Kharji School in Kuwait City. Journal of Education and Practice, 6(3), 136-145.

Bryson, J. M. (2018). Strategic planning for public and nonprofit organizations: A guide to strengthening and sustaining organizational achievement. John Wiley \& Sons.

Chaiken, R., Jenkins, B., Larson, P. Å., Ramsey, B., Shakib, D., Weaver, S., \& Zhou, J. (2008). SCOPE: easy and efficient parallel processing of massive data sets. Proceedings of the VLDB Endowment, 1(2), 1265-1276. https://doi.org/10.14778/1454159.1454166

Gamage, K. A., Silva, E. K. D., \& Gunawardhana, N. (2020). Online delivery and assessment during COVID-19: Safeguarding academic integrity. Education Sciences, 10(11), 301. https://doi.org/10.3390/educsci10110301

Hu, B., Guo, H., Zhou, P., \& Shi, Z. L. (2020). Characteristics of SARS-CoV-2 and COVID-19. Nature Reviews Microbiology, 19, 1-14. https://doi.org/10.1038/s41579-020-00459-7

Lewin, K. (1947). Group decision and social change. Readings in social psychology, 3(1), 197-211.

Menon, J. (2020). COVID-19 and the Poor. Retrieved from https://www.think-asia.org/handle/11540/12447

Mishra, L., Gupta, T., \& Shree, A. (2020). Online teaching-learning in higher education during lockdown period of COVID-19 pandemic. International Journal of Educational Research Open, 1, 100012. https://doi.org/10.1016/j.ijedro.2020.100012

Niemi, H. M., \& Kousa, P. (2020). A case study of students' and teachers' perceptions in a Finnish high school during the COVID pandemic. International journal of technology in education and science. https://doi.org/10.46328/ijtes.v4i4.167

Organisation for Economic Co-operation and Development (OECD). (2020). Evaluating the initial impact of COVID-19 containment measures on economic activity.

Robinson, D. (2019). Becoming a translator: An introduction to the theory and practice of translation. Routledge. https://doi.org/10.4324/9780429276606

Rodriguez-Martinez, A., Zhou, B., Sophiea, M. K., Bentham, J., Paciorek, C. J., Iurilli, M. L., ... Bixby, H. (2020). Height and body-mass index trajectories of school-aged children and adolescents from 1985 to 2019 in 200 countries and territories: a pooled analysis of 2181 population-based studies with 65 million participants. The Lancet, 396(10261), 1511-1524. https://doi.org/10.1016/S0140-6736(20)31859-6 
Sahu, P. (2020). Closure of universities due to Coronavirus Disease 2019 (COVID-19): impact on education and mental health of students and academic staff. Cureus, 12(4), e7541. https://doi.org/10.7759/cureus.7541

Sharifi, A., \& Khavarian-Garmsir, A. R. (2020). The COVID-19 pandemic: Impacts on cities and major lessons for urban planning, design, and management. Science of The Total Environment, 749, 142391. https://doi.org/10.1016/j.scitotenv.2020.142391

Simon, B. (2020). Celebrities are helping the UK's schoolchildren learn during lockdown, World Economic Forum. Retrieved from https://www.weforum.org/agenda/2020/04/pupils-in-the-uk-have-a-new-geography-teacher-sir-david-attenborough

Syed, F. S. (2018). Financial education in schools: policy into practice. Doctoral dissertation, University of Birmingham.

Tam, G., \& El-Azar, D. (2020). Ways the coronavirus pandemic could reshape education. In World Economic Forum. Retrieved from https://www.weforum.org/agenda/2020/03/3-ways-coronavirus-is-reshaping-education-and-what-changes-m ight-be-here-to-stay

The World Bank. (2020). How countries are using edtech (including online learning, radio, television, texting) to support access to remote learning during the COVID-19 pandemic. Retrieved from https://www.worldbank.org/en/topic/edutech/brief/how-countries-are-using-edtech-to-support-remote-learni ng-during-the-covid-19-pandemic

West, M., Kraut, R., \& Ei Chew, H. (2019). I'd blush if I could: closing gender divides in digital skills through education.

World Bank. (2020). COVID-19 to plunge global economy into worst recession since World War II.

Yuan, Z., Xiao, Y., Dai, Z., Huang, J., Zhang, Z., \& Chen, Y. (2020). Modelling the effects of Wuhan's lockdown during COVID-19, China. Bulletin of the World Health Organization, 98(7), 484. https://doi.org/10.2471/BLT.20.254045

Zhang, W., Wang, Y., Yang, L., \& Wang, C. (2020). Suspending classes without stopping learning: China's education emergency management policy in the COVID-19 Outbreak. https://doi.org/10.3390/jrfm13030055

Lederman, D. (2020). The shift to remote learning: The human element. Inside Higher Ed.

Glazerman, S., Nichols-Barrer, I., Valant, J., Chandler, J., \& Burnett, A. (2020). The choice architecture of school choice websites. Journal of Research on Educational Effectiveness, 13(2), 322-350.

https://doi.org/10.1080/19345747.2020.1716905

\section{Copyrights}

Copyright for this article is retained by the author(s), with first publication rights granted to the journal.

This is an open-access article distributed under the terms and conditions of the Creative Commons Attribution license (http://creativecommons.org/licenses/by/4.0/). 